\title{
A PRIMEIRA GUERRA MUNDIAL NA LÍRICA EXPRESSIONISTA
}

\section{Elcio Cornelsen ${ }^{1}$}

Resumo: O objetivo deste artigo é analisar poemas expressionistas cujos autores expressaram, liricamente, suas vivências de guerra como soldados na frente de batalha. Mesmo antes da eclosão da guerra, esta já se prefigurava como uma catástrofe social que, posteriormente, se revelaria em toda a sua virulência. Jovens que vivenciaram o "reino das chamas" e os "labirintos fumegantes da batalha" (Ernst Jünger) encontraram na lírica uma forma apropriada para expressar suas percepções sensoriais sob condições precárias e constante perigo de morte no front. Imagens apocalípticas não eram incomuns. A euforia que predominava também entre os expressionistas com a eclosão da "Grande Guerra" e com a possibilidade de uma transformação social logo se dissipou, à medida que a chamada "guerra de material" revelou-se em toda a sua virulência e horror. Guerra, ódio, miséria, caos, destruição, loucura, violência e morte puderam ser representadas de modo pungente pela estética do Expressionismo.

Palavras-chave: Primeira Guerra Mundial; Expressionismo; Wilhelm Klemm; Hans Leybhold, Alfred Lichtenstein.

Abstract: The aim of this paper is to analyze expressionist poems whose authors offer lyrical accounts of their experiences as soldiers on the battlefront. Even before the First World War outbreak, it already prefigured as some social catastrophe that was subsequently unveiled in all its virulence. Young people who experienced the "empire of the flames" and the "fiery labyrinths of battle" (Ernst Jünger) found in poetry an appropriate way to verbalize their sensory perceptions under precarious conditions and constant death threat on the battlefront. The euphoria that prevailed at the war outbreak among the expressionists, and signaled the possibility of social transformation was soon dispelled, as the so-called "material battle" was revealed in all its bitterness and horror. War, hatred, misery, chaos, destruction, madness, horror, violence, and death could be represented profoundly by means of the expressionist aesthetics.

Keywords: First World War, Expressionism, Wilhelm Klemm, Hans Leybhold, Alfred Lichtenstein.

1 Professor Associado III da Faculdade de Letras da UFMG, nas áreas de Língua e Literatura Alemã (graduação) e de Teoria da Literatura e Literatura Comparada (pós-graduação). Bolsista de Produtividade em Pesquisa do CNPq; cornelsen@ letras.ufmg.br 


\section{INTRODUÇÃO}

Nossa contribuição visa a uma análise de poemas expressionistas, cujos autores vivenciaram a Primeira Guerra Mundial como soldados, médicos ou enfermeiros no front, e procuraram expressar, liricamente, tais vivências de permanente exposição à violência.

Mesmo antes da eclosão da guerra, em 01 de agosto de 1914, esta já se prefigurava como uma catástrofe social e ganhava contornos de horror em inúmeros versos de poetas expressionistas, como, por exemplo, revelam os seguintes versos do poema "A guerra" ("Der Krieg"), de Georg Heym, publicado em 1911:

[...]

Uma grande cidade afundou em amarela fumaça,

Lançou-se no ventre do abismo, silenciosa.

Mas gigantesco sobre as ruínas incandescentes está

Aquele que no céu revolto gira por três vezes sua tocha.

Sobre o reflexo de nuvens de tempestade destroçadas,

Em frias devastações do escuro morto,

Ele ressecou longamente a noite com o incêndio,

Lá embaixo sobre Gomorra gotejam enxofre e fogo. (HEYM, 1959, p. 79-80) ${ }^{2}$

No poema em questão, Georg Heym lança mão da alegoria bíblica da cidade de Gomorra (Gênesis 19), que teria sido destruída pela ira de Deus juntamente com a cidade de Sodoma, com fogo e enxofre, para expressar a guerra - evocada pela paratextualidade do título - e a própria "perdição" à qual a sociedade sob o Império de Guilherme II estaria condenada. Jurista formado, o próprio Heym, aliás, não vivenciou a guerra, pois afogara-se em 16 de janeiro de 1912, quando patinava nas águas congeladas do Havel, nas proximidades de Berlim.

Portanto, essa "prefiguração" lírica da guerra evocada pelo poema de Georg Heym materializou-se, mais tarde, em extrema violência. Jovens que vivenciaram o "reino das chamas" ("Reich der Flammen") e os "labirintos fumegantes da batalha" ("feurige Labyrinthen der Schlacht”), conforme expressões de Ernst Jünger (1978, p. 98 e p. 115), encontraram na lírica uma forma apropriada para expressar suas percepções sensoriais sob condições precárias e constante perigo de morte no front.

2 Todas as traduções, salvo outra indicação, são de nossa autoria. No original, temos:

$[\ldots]$

Eine große Stadt versank in gelbem Rauch

Warf sich lautlos in des Abgrunds Bauch.

Aber riesig über glühnden Trümmern steht,

Der in wilde Himmel dreimal seine Fackel dreht

Über sturmzerfetzter Wolken Widerschein,

Ist des toten Dunkels kalten Wüstenein,

$\mathrm{Daß}$ er mit dem Brande weit die Nacht verdorr,

Pech und Feuer träufet unten auf Gomorrh. 
A título de corpus de análise para o presente estudo, elegemos os seguintes poemas: "A batalha do Marne" (1914; "Schlacht an der Marne"), de Wilhelm Klemm, "Batalha de Saarburg" (1915; "Die Schlacht bei Saarburg"), de Alfred Lichtenstein, e "O terceiro estado" (1914; "Le tiers état"), de Hans Leybhold.

Como constataremos a seguir, imagens apocalípticas são recorrentes em poemas dessa natureza. A euforia que predominava também entre os expressionistas com a eclosão da "Grande Guerra" e com a possibilidade de uma transformação social logo se dissipou, à medida que a chamada "guerra de material" revelou-se em toda a sua virulência e horror. Guerra, ódio, miséria, caos, destruição, loucura, violência e morte puderam ser representadas de modo pungente pela estética do Expressionismo.

Nestes casos, a lírica assume uma função política, mesmo que, de antemão, tais poemas não possam ser tomados como "poemas políticos" stricto sensu. Podemos constatar neles uma crítica contundente à guerra, de modo que, posteriormente, eles contribuíram também para a difusão de uma postura anti-bélica entre os literatos, sobretudo entre escritores orientados por uma política de esquerda.

Diante disso, este breve estudo se pauta tanto por categorias de ordem estética, quanto por categorias de ordem político-social. Nesse sentido, os poemas serão analisados de acordo com a noção de "tendência crítica" ("Kritisierende Tendenz"), proposta por Wolfgang Gast (1973, p. 62) para diferenciar da "tendência afirmativa" ("Affirmierende Tendenz"), pois eles contêm, mesmo que apenas de modo implícito, uma crítica às relações de poder da época, que culminaram com a eclosão da guerra.

Além disso, este estudo deve levar em conta também as possibilidades estéticas de expressão da guerra. Poderíamos afirmar, sem dúvida, que elas se situam na própria natureza do Expressionismo. Como já havia salientado Lothar Schreyer (2004, p. 170), dramaturgo e editor da revista Der Sturm ("A Tempestade") durante a guerra, o Expressionismo seria "o movimento espiritual de um tempo que coloca a vivência interior acima da vida exterior" ("die geistige Bewegung einer Zeit, die das innere Erlebnis über das äußere Leben stellt").

Os autores eleitos para este estudo foram colaboradores da revista "A Ação" (Die Aktion): Wilhelm Klemm, Alfred Lichtenstein e Hans Leybhold, este último, inclusive, editor da revista Die Revolution ("A Revolução”). Em 1914, segundo o teórico alemão Paul Raabe (1964, p. 13), a revista tornou-se "o centro da poesia anti-bélica" ("das Zentrum der Antikriegsdichtung”). A partir da eclosão da guerra, a Die Aktion possuía até mesmo uma coluna com o título "Versos do campo de batalha" ("Verse vom Schlachtfeld" "), na qual os poetas anunciavam a destruição, o perigo de morte e a miséria do front. Para o editor Franz Pfemfert, segundo Paul Raabe um combatente ferrenho do Kaiserreich (RAABE, 1964, p. 13), cada vez mais, a poesia colocou-se a serviço da política. Diante disso, o presente estudo orientar-se-á também por uma noção de “engajamento político" (“Politisches Engagement”), conforme proposto por Wolfgang Gast (1973, p. 74) ao levar em conta, em seu estudo sobre poesia política alemã, a distinção entre o "político da mesa de bar" (“Stammtischpolitiker”), daquele que de fato se engaja por uma causa, podendo chegar até à filiação partidária ou mesmo ao vínculo a um outro tipo de organização política.

Podemos, ainda, ressaltar que tomar os poemas em questão como objeto de estudo acompanha uma tendência presente nas pesquisas sobre a Primeira Guerra Mundial, que 
se pautam, sobretudo, pela chamada "vivência de guerra" ("Kriegserlebnis") daqueles que estiveram nos campos de batalha, e se orientam por um viés sociológico dentro do debate historiográfico, conforme aponta Gerhard Hirschfeld (2004, p. 9).

\section{VERSOS DE POETAS SOLDADOS SOBRE O FRONT}

Iniciaremos nossa análise pelo poema "Batalha do Marne" (1914; "Schlacht an der Marne"), de Wilhelm Klemm. Formado em medicina, Wilhelm Klemm tomou parte na guerra, de 1914 a 1918, como tenente médico, assim como outros escritores alemães, como Gottfried Benn e Alfred Döblin. Suas vivências nos hospitais de campanha e no front ocidental possibilitaram-lhe conhecer de perto os horrores da guerra e encontraram eco em seus poemas escritos no período e reunidos nas obras Gloria! (1915), Verse und Bilder (1916; "Versos e imagens") e Aufforderung (1917; "Exortação"). Tais vivências ecoam no poema "Batalha do Marne", publicado na edição de 24 de outubro de 1914 na revista expressionista Die Aktion:

Vagarosamente as pedras começam a se mover e a falar.

Os gramados se enrijecem em verde metal. Os bosques,

Baixos, densos esconderijos, devoram colunas distantes,

O céu, o segredo branco feito calcário, ameaça rebentar.

Duas horas colossais correm feito minutos.

O horizonte vazio incha-se ao ar,

Meu coração é tão grande como a Alemanha e a França juntas,

Perfurado por todos os projéteis do mundo.

A bateria eleva seu rugido,

Seis vezes para fora na terra. As granadas uivam.

Silêncio. Ao longe fervilha o fogo da infantaria,

Por dias, por semanas. (KLEMM, 1964, p. 200) ${ }^{3}$

\footnotetext{
3 No original, temos:

Langsam beginnen die Steine sich zu bewegen und zu reden.

Die Gräser erstarren zu grünem Metall. Die Wälder,

Niedrige, dichte Verstecke, fressen ferne Kolonnen.

Der Himmel, das kalkweiße Geheimnis, droht zu bersten.

Zwei kolossale Stunden rollen sich auf zu Minuten.

Der leere Horizont bläht sich empor,

Mein Herz ist so groß wie Deutschland und Frankreich zusammen,

Durchbohrt von allen Geschossen der Welt.

Die Batterie erhebt ihre Löwenstimme,

Sechsmal hinaus in das Land. Die Granaten heulen.

Stille. In der Ferne brodelt das Feuer der Infanterie,

Tagelang, wochenlang.
} 
Como podemos depreender desses versos, a vivência de guerra faz com que o eu lírico demonstre sua perplexidade numa imagem que destroi uma suposta paisagem idílica de tempos de paz. A natureza surge como que atingida profundamente pelo cotidiano da guerra, como parte ativa e personificada da destruição ("Os gramados se enrijecem em verde metal. Os bosques/ Baixos, densos esconderijos, devoram colunas distantes"). No centro, está o eu lírico, numa imagem tradicional que lança mão do coração para potencializar seu sentimento ("Meu coração é tão grande como a Alemanha e a França juntas,/ Perfurado por todos os projéteis do mundo."), e a subjetividade se faz presente também na percepção do tempo ("Duas horas colossais correm feito minutos").

Todavia, não se trata de um evento cotidiano do front, mas sim de uma batalha em especial, materializada na paratextualidade do título: "Batalha do Marne". A primeira batalha às margens do rio Marne, afluente do rio Sena, ocorreu durante a fase inicial de ofensiva do exército alemão sobre o território francês, de 05 a 12 de setembro de 1914. Essa batalha entrou para os anais da história da Primeira Guerra por ter representado o primeiro revés no avanço das tropas alemãs, diante da contra-ofensiva franco-britânica que, assim, obteve seu primeiro êxito, forçando o recuo do inimigo e pondo um fim aos planos do Marechal von Moltke de derrotar a França em poucas semanas. De acordo com o historiador britânico John Keegan (2004, p. 126), “[n]enhum dos cursos d’água constituía sério obstáculo. Contudo, eles definiam as linhas nas quais a ação deveria ser conjunta e requeriam preparações para deliberar o ataque”. Segundo o historiador francês Marc Ferro (1992, p. 94), “[a] nimados pelo mais ardente patriotismo, os exércitos dos dois campos bateram-se com igual denodo, sofrendo ambos baixas consideráveis". O custo de vidas humanas foi elevado para todas as partes envolvidas na batalha: cerca de 80.000 soldados franceses e 1.700 soldados ingleses caíram mortos, e foi registrado um total de 250.000 baixas nas tropas alemãs, entre mortos, feridos e detidos.

Certamente, como médico de campanha, Wilhelm Klemm vivenciou num curto espaço de tempo - uma semana - uma carnificina que produziu muitos mortos e feridos. Seus versos procuram dar conta desse morticínio, mas primeiro precisa vencer a própria dificuldade de expressar o horror: "Vagarosamente as pedras começam a se mover e a falar." Nada, entre o céu e a terra, fica incólume à destruição, captada visual e sonoramente pelo eu lírico. E essa destruição não é somente exterior, pois seu coração se torna um campo de batalha e, ao mesmo tempo, um alvo "[p]erfurado por todos os projéteis do mundo".

Além disso, nota-se pelos versos que o eu lírico é um soldado que assume certos traços de aclimatação ao ambiente da guerra: observa o que ocorre ao seu redor e distingue a sequência de disparos e o tipo de projétil. Mas mesmo com os sentidos aguçados que lhe lançam quase que ao estado instintivo, ainda resta nele um sentimento que remete ao humano, que não distingue em seu coração dilacerado os beligerantes.

Posto isso, passemos ao segundo poema eleito para análise neste breve estudo: "Batalha de Saarburg" (1915; "Die Schlacht bei Saarburg"), de Alfred Lichtenstein, publicado em 27 de fevereiro de 1915 na revista Die Aktion: 
A terra embolora na neblina.

A noite pressiona feito chumbo.

Ao redor rasga o estampido elétrico

e gemendo rompe tudo em dois.

Como maus farrapos fumegam

os povoados no horizonte.

Eu jazo abandonado por Deus,

nas trincheiras crepitantes do front.

Vários passarinhos de cobre inimigos

zunem ao redor do coração e do cérebro.

Eu me ergo no alvorecer

e ofereço à morte minha testa. (LICHTENSTEIN, 1964, p. 208) ${ }^{4}$

No poema de Alfred Lichtenstein, o eu lírico, soldado na frente de batalha, jaz numa trincheira próximo de Saarburg na região da Lorena, como indica o título. Perplexo, ele descreve seu entorno, vislumbrando ao longe os povoados sendo devorados pelas chamas.

Assim como no poema de Wilhelm Klemm, a natureza ganha destaque logo na primeira estrofe de "A batalha de Saarburg": "A terra embolora na neblina." E o tempo parece transcorrer da escuridão da noite para o alvorecer: "A noite pressiona feito chumbo./ [...] Eu me ergo no alvorecer".

Por sua vez, os versos da segunda estrofe apresentam o cenário de destruição: "Como maus farrapos fumegam/ os povoados no horizonte". O eu lírico se sente só e abandonado em sua posição de defesa: "Eu jazo abandonado por Deus,/ nas trincheiras crepitantes do front."

$\mathrm{Na}$ terceira estrofe, a metáfora dos "Vários passarinhos de cobre inimigos" que "zunem ao redor do coração e do cérebro" remete às balas que passam zunindo perto do eu lírico e que lhe atingem o pensamento e o sentimento. Já os últimos dois versos do poema parecem indicar um ato suicida do eu lírico que se expõe à morte, ao erguer-se da trincheira, tornando-se alvo fácil: "Eu me ergo no alvorecer/ e ofereço à morte minha testa."

\footnotetext{
4 No original, temos:

Die Erde verschimmelt im Nebel.

Der Abend drückt wie Blei.

Rings reißt elektrisches Krachen

und wimmernd bricht alles entzwei.

Wie schlechte Lumpen qualmen

die Dörfer am Horizont.

Ich liege gottverlassen

in der knatternden Schützenfront.

Viel kupferne feindliche Vöglein surren um Herz und Hirn.

Ich stemme mich steil in das Graue und biete dem Tode die Stirn.
} 
Cabe ressaltar que, segundo nota do editor Paul Raabe (1964, p. 208), "A batalha de Saarburg" é o último poema de Alfred Lichtenstein. O telegrama de campanha que Lichtenstein enviara do front ao editor contendo o poema data de 16 de setembro de 1914 e foi recebido por Franz Pfemfert no final de outubro daquele ano. Juntamente com Georg Heym, Jakob van Hoddis e Ernst Blass, Alfred Lichtenstein foi um dos principais poetas do Expressionismo em Berlim. Formado em Direito um ano antes do início da guerra, já havia publicado uma coletânea de poemas: "Crepúsculo" (Dämmerung). Poucos dias após ter escrito o poema, caiu morto no dia 25 de setembro de 1914, em batalha próxima à cidade francesa de Reims. Aquela inquietação do eu lírico aplacado pelos tiros ao seu redor, numa apreensão multi-sensorial daquele que ouve e vê a guerra, e que se expõe à morte, se concretizaria.

Podemos identificar outras semelhanças desse poema com "Batalha do Marne": o eu lírico, em ambos os poemas, demonstra o embate de forças entre o lado por assim dizer "instintivo" e o lado sentimental. Se o eu lírico de Wilhelm Klemm tem seu coração dilacerado, o eu lírico de Alfred Lichtentstein não suporta o horror e oferece-se à morte.

Por fim, como terceiro exemplo da lírica expressionista que retrata a guerra, elegemos o poema "Le tiers état" (1914; "O terceiro estado"), de Hans Leybhold, publicado postumamente em 26 de setembro de 1914 na revista Die Aktion:

Pisoteados, que se esbofeteiam através de escuridões.

Nós sangrentos! Abjetos ressecam nossos membros.

A noite deita-se ao nosso redor; como falsas asas angelicais

ela cai em negros caudais; novamente

ela cobre as feridas, a miséria e as dores.

Nós sedentos! Nenhuma fonte sacia nossa sede ardente.

Nós tramamos a sanha. As velas fumegam cinzentas

em nossos porões. Maldita saciedade! Nossas mãos

cerradas fortemente. Só de vez em quando nos brilha a lua:

símbolo nascente do obeso que habita vivendas.

O ódio torna fraco! E forte ao mesmo tempo. Para que leis?

Nós mordemos aflitos nossa língua em chagas.

Sobrecarregados: nós olhamos para o mais profundo leito

do mar do tempo. Lá crescem os nossos futuros tesouros. (LEYBHOLD, 1964, p. 195)

5 No original, temos:

Zertretene, die sich durch Finsternisse prügeln.

Wir Blutigen! Verworfen dorren unsre Glieder.

Die Nacht legt sich um uns; erlognen Engelsflügeln

gleich fällt sie in schwarze Flüsse; wieder

deckt sie die Wunden zu, wie die Not und Schmerzen.

Wir Durstigen! Kein Quell stillt unsre Brände.

Wir brüten Wut. Es qualmen grau die Kerzen

in unsern Kellern. Verfluchte Sattheit! Unsre Hände

hart geballt. Nur manchmal leuchtet uns der Mond:

gequollenes Symbol des Feisten, der in Villen wohnt.

Der Haß macht schwach! Und stark zugleich. Wozu Gesetze?

Wir beißen uns gequält die Zunge wund.

Belastete: wir sehen auf den tiefsten Grund 
Escrito nas primeiras semanas da guerra, o poema parece centrar-se nas apreensões de um eu lírico que vê naqueles que sofrem - "sangrentos", "sedentos", "sobrecarregados" o "terceiro estado", indicado pela paratextualidade do título que remete à tradição da França revolucionária. Diferindo dos poemas anteriores, este não se refere a uma batalha em especial, e nem expressa as apreensões do eu lírico em situação de conflito. Ao contrário, predomina certo caos de sensações, num oscilar de sentimentos que vai do questionamento - "Para que leis?" até um tom de esperança - "Lá crescem os nossos futuros tesouros".

O espaço é incerto e em certo momento indica "porões". Mas parece ser ao ar livre, numa noite escura - "A noite deita-se ao nosso redor; como falsas asas angelicais/ ela cai em negros caudais; novamente/ ela cobre as feridas, a miséria e as dores." O espaço se apresenta como marcado por privações, em que há feridos, sedentos e aflitos, podendo ser bem uma trincheira, ocupada pelo "terceiro estado" que não participa do poder e sofre as consequências de uma política de beligerância.

Todavia, diferindo dos poemas de Wilhelm Klemm e de Alfred Lichtenstein, "Le tiers état" apresenta um eu lírico que não centra a percepção em si próprio, mas se vê como parte de um grupo de desafortunados - "Nós sangrentos"; "Nós mordemos aflitos nossa língua em chagas"; "Nós olhamos para o mais profundo leito do mar do tempo". E é nesse gesto da memória que suspende momentaneamente a apreensão do aqui e agora que parece residir uma centelha de esperança para "futuros tesouros" - uma revolução? Entretanto, pouco tempo depois, em 08 de setembro de 1914, Hans Leybhold morreu no Hospital Militar da Guarnição de Itzehoe, na Alemanha, onde havia servido ao exército em 1911, quando passara para a reserva como aspirante a tenente. Após ser ferido gravemente durante uma ação do exército alemão nas proximidades da cidade francesa de Namur, Leybhold foi enviado para o Hospital Militar de Itzehoe em 05 de setembro. Segundo consta, teria cometido suicídio ao atirar contra si próprio.

\section{CONSIDERAÇÕES FINAIS}

A análise dos poemas "Batalha do Marne", de Wilhelm Klemm, "A batalha de Saarburg", de Alfred Lichtenstein e "Le tiers etát", de Hans Leybhold demonstrou que eles apresentam alguns aspectos em comum. O primeiro deles diz respeito ao modo crítico com que se constrói o ponto de vista do eu lírico. São poemas que reiteram os significados da guerra como violência, destruição e morte. Neles, não encontramos termos como "nação", "herói", "pátria", presentes em poemas que afirmam a guerra. Ao contrário, a terminologia que remete à violência e à destruição é abundante: morte, sangue, miséria, feridas e dor.

Inegavelmente, como aponta o historiador Gerhard Hirschfeld (2004, p. 9), "os ideais propagados no início da guerra, da coragem individual e do sacrifício incondicional pela pátria tornaram-se rapidamente obsoletos", pois "a luta heróica sob as condições da guerra de trincheiras reduziu-se à experiência do frio, da lama e da umidade, de conviver com insetos e doenças, e as tentativas desesperadas de sobreviver à artilharia e às granadas".

Sem dúvida, a estética do Expressionismo revelou-se adequada à construção do ponto de vista adotado nos poemas, potencializando o poder de destruição da guerra em imagens

des Meers der Zeit. Dort wachsen unsre Zukunftsschätze. 
onde predominam o caos, o sofrimento e a morte. Tal estética, marcada pelo grotesco, o feio e o dissonante se mostrou plenamente apropriada a expressar os horrores da guerra.

Por fim, cabe ressaltar que Wilhelm Klemm, Alfred Lichtenstein e Hans Leybhold, todos colaboradores da revista Die Aktion, não só vivenciaram de perto a guerra, como logo perceberam que a euforia inicial demonstrada por amplas camadas da sociedade do Kaiserreich se dissipou nas batalhas sangrentas de uma guerra que conhecia, pela primeira vez, novas armas com poderes de destruição que podiam vitimar milhares de soldados em espaços reduzidos e em pouco tempo. Dois deles pereceram - Lichtenstein e Leybhold, e o outro vivenciou a carnificina entre 1914 e 1918 em hospitais de campanha - Klemm. Mas todos, enquanto puderam, criticaram a partir de suas vivências no campo de batalha aquele status quo definido já em 1912 de modo acurado por Franz Pfemfert (1964, p. 57-58), editor da revista Die Aktion: “A loucura [da Europa] parece incurável. Ela pode até por algum tempo ficar escondida debaixo de uma camada de lixo cultural, mas reconhecemos em toda parte os sintomas inconfundíveis de sua presença (um confuso cintilar de uniformes, sabres e baionetas)". Tomando as categorias propostas por Wolfgang Gast (1973, p. 62), podemos afirmar que todos esses poetas criticam as relações de poder da época, que culminaram com a eclosão da guerra, e também o próprio ato insensato da guerra em si, enquadrando-se, portanto, na "tendência crítica" ("Kritisierende Tendenz"). Inegavelmente, cada um ao seu modo e em seu tom, os poemas aqui analisados documentam o engajamento de seus autores contra essa loucura que assolou a Europa no início do século XX e que custou a vida de milhões, materializando o grotesco e a catástrofe que já se prenunciavam através da literatura e da arte expressionista.

\section{REFERÊNCIAS}

BEST, Otto F. (org.). Expressionismus und Dadaísmus. Stuttgart: Philipp Reclam, 1996.

BEST, Otto F. (org.). Theorie des Expressionismus. Stuttgart: Philipp Reclam, 2004.

CORNELSEN, Elcio; BURNS, Tom. (org.). Literatura e Guerra. Belo Horizonte: Ed. UFMG, 2010.

CORNELSEN, Elcio; BURNS, Tom; JAECKEL, Volker; VIEIRA, Luis Gustavo Leitão (org.). Revisiting 20th Century Wars. Stuttgart: ibidem, 2012.

FERRO, Marc. História da Primeira Guerra Mundial 1914-1918. Trad. Artur Lopes Cardoso, Rio de Janeiro: Edições 70, 1992.

GAST, Wolfgang. Politische Lyrik: Deutsche Zeitgedichte des 19. und 20. Jahrhunderts. Stuttgart: Philipp Reclam, 1973.

GAST, Wolfgang. Systematische Übersicht über die Gedichte. Arbeitsvorschläge. In: GAST, Wolfgang. Politische Lyrik: Deutsche Zeitgedichte des 19. und 20. Jahrhunderts. Stuttgart: Philipp Reclam, 1973, p. 61-78. 
HEYM, Georg. Der Krieg [1911]. In: PINTHUS, Kurt (org.). Menschheitsdämmerung: ein Dokument des Expressionismus. Hamburg: Rowohlt, 1959, p. 79-80.

HIRSCHFELD, Gerhard. Der Erste Weltkrieg in der deutschen und internationalen Geschichtsschreibung. Aus Politik und Zeitgeschichte: Beilage zur Wochenzeitung Das Parlament. B-29-30/2004, p. 3-12, 12 de julho de 2004.

JÜNGER, Ernst. In Stahlgewittern. Aus dem Tagebuch eines StoBtruppführers. Sämtliche Werke: Tagebücher. v. 1, Stuttgart: Klett, 1978.

KEEGAN, John. História ilustrada da Primeira Guerra Mundial. Trad. Renato Rezende, Rio de Janeiro: Ediouro, 2004.

KLEMM, Wilhelm. Schlacht an der Marne [24.10.1914]. In: RAABE, Paul. Ich schneide die Zeit aus: Expressionismus und Politik in Franz Pfemferts ,Aktion'. München: dtv, 1964, p. 200.

LEYBHOLD, Hans. Le tiers état [26.09.1914]. In: RAABE, Paul. Ich schneide die Zeit aus: Expressionismus und Politik in Franz Pfemferts ,Aktion'. München: dtv, 1964, p. 195.

LICHTENSTEIN, Alfred. Die Schlacht bei Saarburg [27.02.1915]. In: RAABE, Paul. Ich schneide die Zeit aus: Expressionismus und Politik in Franz Pfemferts ,Aktion'. München: dtv, 1964, p. 208.

PFEMFERT, Franz. Europas Wahnsinn. In: RAABE, Paul. Ich schneide die Zeit aus: Expressionismus und Politik in Franz Pfemferts ,Aktion'. München: dtv, 1964, p. 57-59

PINTHUS, Kurt (org.). Menschheitsdämmerung: ein Dokument des Expressionismus. Reinbek bei Hamburg: Rowohlt, 1959.

RAABE, Paul. Einleitung. In: RAABE, Paul (org.). Ich schneide die Zeit aus. Expressionismus und Politik in Franz Pfemferts ,Aktion'. München: dtv, 1964, p. 7-15.

RAABE, Paul (org.). Ich schneide die Zeit aus: Expressionismus und Politik in Franz Pfemferts, Aktion'. München: dtv, 1964.

SCHREYER, Lothar. Expressionistische Dichtung [1918]. In: BEST, Otto F. (org.). Theorie des Expressionismus. Stuttgart: Philipp Reclam, 2004, p. 170-181. 